\title{
Predicting Fracture Mechanisms in Synthetic Foam Sandwiches with Multi-Layered Cores Using Extended Cohesive Damage Model
}

\author{
S Ghimire and J Chen* \\ School of Civil Engineering and Surveying \\ University of Portsmouth, Portsmouth PO1 3AH, UK \\ *Corresponding address: jiye.chen@ port.ac.uk
}

Key words: Functionally graded sandwiches, Multi-layered core, Extended cohesive damage model, Predictive shear failure modelling

\begin{abstract}
This paper introduces an investigation on fracture mechanisms of synthetic foam sandwiches with graded multi-layered cores. The extended cohesive damage model (ECDM) is used in investigating detailed fracture mechanisms of this kind of synthetic foam sandwich panels under quasi-static 3-point bending. The ECDM prediction shows very good agreements with experimental work on investigating the sandwiches with homogeneous core and the core with four graded layers. This investigation has found that the failure modes of sandwich panels with multi-layered cores are sliding shear failure dominated fracture in the core along the path above the core-bottom sheet interface instead of pure debonding at interfaces. It has been also found an excellent mechanical performance when the core has multiple graded layers in the investigated sandwiches compared to the case of homogenous core. It is the first time that the correlation between loading capacity and number of graded layers in the core of the investigated synthetic foam sandwiches is explored. The ECDM predicted loading capacity of the investigated sandwich panel with an 8 -layered core is increased by $70 \%$ compared to a homogenous core. This investigation also shows that the ECDM is a robust tool for predicting fracture mechanisms of synthetic foam sandwiches.
\end{abstract}




\section{Nomenclature}

\begin{tabular}{|c|c|}
\hline $\mathbf{a}_{\mathrm{i}}$ & Additional degree pf freedoms \\
\hline $\mathrm{CZM}$ & Cohesive Zone Model \\
\hline $\mathrm{d}$ & Damage scale factor \\
\hline ECDM & Extended Cohesive Damage Model \\
\hline $\mathbf{f}_{\text {coh }}$ & Cohesive force vector \\
\hline$f_{\text {ext }}^{\mathrm{a}}$ & Equivalent nodal force vector for enriched freedoms \\
\hline $\mathbf{f}_{\mathrm{ext}}^{\mathrm{u}}$ & Equivalent nodal force vector for standard FEM freedoms \\
\hline $\mathrm{G}_{\mathrm{c}}$ & Total fracture energy \\
\hline $\mathrm{G}_{\mathrm{Ic}}$ & Mode-I Fracture energy \\
\hline $\mathrm{G}_{\text {IIc }}$ & Mode-II Fracture energy \\
\hline $\mathrm{H}_{\Gamma_{d}}$ & Heaviside function \\
\hline $\mathrm{i}$ & Standard degree freedoms \\
\hline $\mathrm{j}$ & Enriched degree freedoms \\
\hline $\mathbf{K}^{\mathrm{aa}}$ & Stiffness matrix associated with the enriched FE approximation \\
\hline $\mathbf{K}^{\mathrm{uu}}$ & Stiffness matrix associated with the standard FE approximation \\
\hline $\mathbf{K}^{\mathrm{ua}} / \mathbf{K}^{\mathrm{au}}$ & Coupling between enriched approximation and standard FE approximation \\
\hline $\mathrm{L}_{1}$ & Effects from enrichment \\
\hline $\mathrm{L}_{2}$ & Effects from cohesive force \\
\hline$l_{\text {crack }}$ & Characteristic length of a crack \\
\hline $\mathrm{N}$ & Interpolation function \\
\hline $\mathrm{N}_{\mathrm{i}}$ & Enriched FEM shape functions \\
\hline $\mathrm{t}_{0}$ & Initial cohesive traction \\
\hline$\overline{\mathbf{t}}$ & External traction \\
\hline $\mathbf{t}_{0}^{n}$ & Initial normal traction components \\
\hline $\mathbf{t}_{0}^{S}$ & Initial shearing traction components \\
\hline $\mathbf{t}_{\text {coh }}^{n}$ & Cohesive tractions in local normal direction \\
\hline $\mathbf{t}_{\text {coh }}^{S}$ & Cohesive tractions in local tangential direction \\
\hline $\mathbf{u}_{\mathrm{i}}$ & Displacement at enriched degree freedom $\mathrm{j}$ \\
\hline $\mathbf{u}(\mathbf{x})$ & Displacement field \\
\hline XFEM & eXtended Finite Element Method \\
\hline $\mathbf{X}_{\mathrm{i}}$ & Coordinate for the $\mathrm{i}^{\text {th }}$ node \\
\hline$\Gamma^{\mathrm{h}}$ & A boundary \\
\hline$\Gamma_{\mathrm{d}}$ & Discontinuity \\
\hline$\Gamma_{\text {coh }}^{\text {crack }}$ & Cohesive crack surface \\
\hline$\Delta \delta$ & Displacement jump \\
\hline$\Phi(\mathbf{x})$ & Enriched function for discontinuity \\
\hline$\tau_{0}$ & Initial traction \\
\hline$\varepsilon_{0}$ & Initial damage strain \\
\hline $\mathbf{\Omega}$ & Domain of the investigated object \\
\hline $\boldsymbol{\Omega} \cdot / \mathbf{\Omega}^{+}$ & Separated two sides of the domain by a cohesive crack \\
\hline$\Re$ & An operator that represents ultimate equilibrium \\
\hline
\end{tabular}




\section{Introduction}

A typical composite sandwich panel is designed with two thin face sheets having very high strengths, which are connected by a thick core of low density $[1,2]$. Composite sandwiches show good mechanical properties hence they are widely used in various engineering structures in civil, aerospace, and automotive industries, etc. [1]. Usually synthetic foam cores and honeycomb cores are used for different applications, for example the foam core based sandwich is used in cladding panels [3], floors in buildings [4], decks in bridge structures [5, 6], wind turbine blades [6] and ship buildings [7], whilst the honeycomb core based sandwich is used to manufacture various parts in aerospace, automobile and sporting [8-10]. Usually, sandwich panels have fracture problems in the core close to the core-face sheet interfaces due to high value of concentrated shear stresses near the interface region when they are exposed to different types of loadings [11], or they are prone to fracture in the core close to the interfaces due to mismatched material properties between the core and face sheets [1]. Functionally graded sandwich panels (FGSP) were proposed in the past few decades to mitigate those problems by reducing the gap between mismatched material properties. In FGSP, material properties are varied overall in the core of composite sandwiches through non-uniform distribution of material properties. FGSP requires more energy to split the sandwich panels compared to conventional sandwich panels because of their multiple fractures modes. It was argued by [12] that functionally graded cores will significantly decrease the normal and shear strains and it also reduces deflection and magnitude of stress by eliminating discontinuity across the interface between the core and the laminates [13].

There is a lot of previous researches focused on the development of functionally graded material (FGM) in which different materials were mixed in different grades but not designed as functionally graded layers $[1,14,15]$. Likewise, other investigations based on various experimental approaches were conducted to study the performance of sandwich panels with 
functionally graded cores $[16,17]$. The effect of varying foam core density on the bending response of sandwiches was studied experimentally by [16]. It was found that bending resistance and stiffness of synthetic foam sandwiches with graded 4-layered cores are improved compared to traditional sandwiches with homogeneous cores. However, it would not a costeffective way to carry out investigations through experimental work to fully study and optimize the behaviour of sandwiches. On the other hand, previous analytical approaches based on various plate theories such as two and three-dimensional elasticity equations, polynomial equations, classical deflection formulae and third-order zig-zag models were conducted to analyse mechanical behaviour of simple sandwich samples $[12,13,18,19]$, but it is not easy to use them to predict detailed fracture mechanisms at the structural level. Hence, it can be argued that numerical modelling is an efficient and effective approach to predict the behaviour of FGSP.

It is challenging to predict detailed fracture mechanisms of composite sandwiches particularly FGSP with multi-layered cores due to their complex failure modes, different types of cracks as well as unknown fracture paths. There are several different approaches, e.g. cohesive zone model (CZM) [20, 21] and extended finite element method (XFEM) [22], that were in practice for decades in the prediction of discontinuities in various structures. These techniques have some shortfalls due to their limited functions and features. For example, CZM needs prior defined crack paths and large computational work in nonlinear iteration, and it quite often meets convergent problems in simulating crack propagation at the structural level. Likewise, the current XFEM has a limited special function in defining the displacement field at the crack front; it can predict a single type of crack. This method needs large CPU time because of additional enriched degree of freedoms used for discontinuities [23, 24]. Oliver et al. [25] investigated an embedded finite element method (E-FEM) which has implementation of elemental enrichments rather than the nodal enrichments required by XFEM to improve 
accuracy. A variational multiscale cohesive method (VMCM) [26] is another elemental enrichment method to improve accuracy. Lin et al. developed a continuum de-cohesive finite element (CDFE) in 2019 [27], which has similarities to the method of extended cohesive damage model (ECDM) developed by Li \& Chen [23, 24, 28-30] in 2017. Both CDFE and ECDM have implementation of enrichments at elemental level, unlike E-FEM and VMCM, fully condensed equilibrium equations are applied to improve efficiency. In both CDFE and ECDM, introduced enriched degrees of freedom (DOFs) are condensed into equivalent stiffness matrix such that the methods can be implemented into standard FEM framework to improve the computational efficiency. And, the crack initiation and propagation in both methods are based on cohesive crack growth. The major difference between the two methods are stated as follows. On a methodological level, CDFE is inspired by VMCM while the ECDM is motivated from XFEM. In CDFE, cohesive crack is physically introduced into the element while in ECDM, like XFEM, the crack is represented by enriched DOFs without being physically inserted into the element. In this way, the partition of unity (POU) in CDFE is for cohesive crack insertion while that in ECDM is solely for numerical integration in subdomains. Also, due to this difference, the damage factor in CDFE is based upon physical crack separation, through the traction-separation law, while that in ECDM, the cohesive law is related to the strain field. On a numerical implementation level, the current CDFE is developed within an explicit framework, using Abaqus subroutine VUEL. The ECDM is developed within an implicit framework with significant accuracy and efficiency, using Abaqus subroutine UEL.

In ECDM formulations, enriched DOFs are condensed after crack initiation and the crack opening follows the cohesive behaviour without the crack-tip enrichment in XFEM for singular crack-tip stress distribution. After condensation, an equivalent stiffness matrix is obtained such that the method can be implemented with standard FEM codes [23, 24, 28-30]. Various problems of composite materials have been studied with ECDM including fracture benchmark 
specimens, four point bending of a stiffened laminated composite panel, crack propagation in a composite $\mathrm{T}$-joint and delamination migration in composite beams [24-26]. Through the studied examples, the effectiveness, robustness and efficiency of the method have been shown. ECDM reduces the CPU time of prediction by more than $90 \%$ and $60 \%$ compared to CZM and XFEM, respectively based on the same investigated specimens [28, 30]. Unlike CZM, predefined crack paths are no longer required by ECDM and ECDM has no convergent problems in nonlinear fracture analysis of investigated composite samples [24, 28, 29].

This investigation focuses on the synthetic foam core sandwiches. The ECDM is chosen to predict the fracture mechanisms of foam core sandwich panels with homogenous core and the core with multiple graded layers. The validation of ECDM predictions is completed by comparison with existing experimental work. Through detailed analysis of fracture mechanisms in basic foam core sandwiches, a graded multi-layered core with proportionally varied material properties is proposed by this investigation for enhancing damage resilience in foam core sandwiches.

\section{Methodology}

In this investigation, a user defined ECDM subroutine is applied through a finite element commercial package ABAQUS to explore the non-linear damage behaviour of synthetic foam core sandwiches. A brief introduction to the ECDM formulations is given below, its more details can be referred to the $[24,28,29]$. The fundamental base of ECDM is within the framework of XFEM, unlike XFEM additionally enriched DoFs are eliminated at the element level where a common cohesive damage model is embedded. A fully condensed equilibrium equation with the effects from enriched DoFs and cohesive forces is achieved for solving nonlinear damage evolution problems. The displacement field in ECDM can be expressed as:

$$
\mathbf{u}(\mathbf{x})=\sum_{i \in I} N_{i}(\mathbf{x}) \mathbf{u}_{i}+\Phi(\mathbf{x})
$$

Where, $\Phi(\mathbf{x})$ is enriched function for discontinuity and expressed as: 


$$
\boldsymbol{\Phi}(\mathbf{x})=\sum_{i \in J} N_{j}(\mathbf{x})\left(\mathrm{H}_{\Gamma_{d}}(\mathbf{x})-\mathrm{H}_{\Gamma_{d}}\left(\mathbf{x}_{i}\right)\right) \mathbf{a}_{i}
$$

Where, nodes $\mathrm{i}$ and $\mathrm{j}$ are for standard degree freedoms and enriched degree freedoms respectively, $\mathbf{x}_{i}$ is the position coordinate for the $i^{\text {th }}$ node, $\mathrm{N}_{\mathrm{i}}$ and $\mathrm{N}_{\mathrm{j}}$ is standard FEM shape functions, $\mathbf{u}_{\mathrm{i}}$ is displacement, $\mathbf{a}_{\mathrm{i}}$ is additional DoFs and $\mathrm{H}_{\Gamma_{d}}$ represents Heaviside function as presented in Equ. 3 where $\Omega^{+}$and $\Omega^{-}$represents two different sides of the domain from the discontinuity $\Gamma_{\mathrm{d}}$.

$$
\mathrm{H}_{\Gamma_{d}}(\mathbf{x})= \begin{cases}1 & \mathrm{x} \in \Omega^{+} \\ 0 & \mathrm{x} \in \Omega^{-}\end{cases}
$$

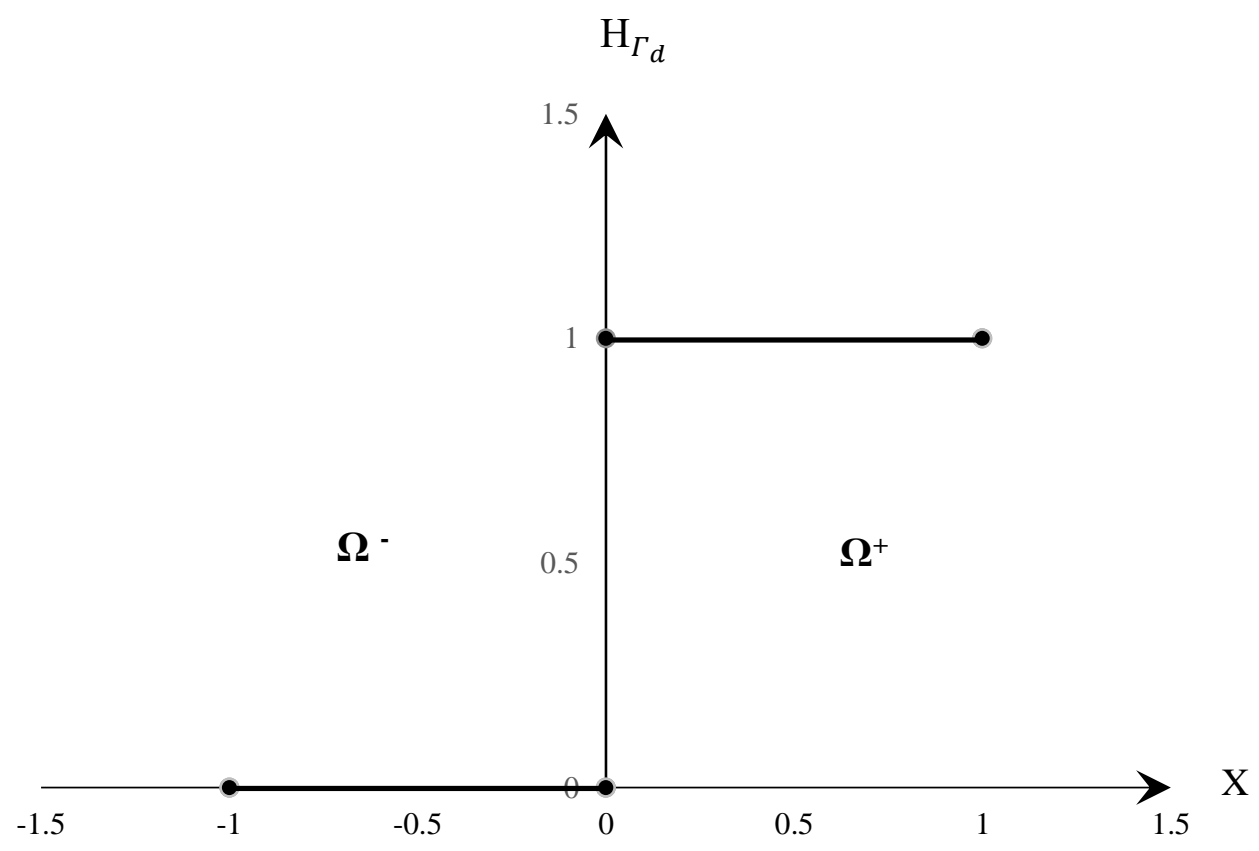

Fig. 1: A basic Heaviside function

Fig. 1 schematically presents a basic Heaviside function. A discrete equilibrium equation based on Bubnov-Galerkin method for the weak form for static analysis can be expresses as:

$$
\left[\begin{array}{ll}
\mathbf{K}^{u u} & \mathbf{K}^{u a} \\
\mathbf{K}^{a u} & \mathbf{K}^{a a}
\end{array}\right]\left[\begin{array}{l}
\mathbf{u} \\
\mathbf{a}
\end{array}\right]=\left[\begin{array}{l}
\mathbf{f}_{e x t}^{u} \\
\mathbf{f}_{e x t}^{a}
\end{array}\right]
$$


Where, the equivalent nodal force vectors are expressed by $\mathbf{f}_{e x t}^{\mathrm{u}}$ and $\mathbf{f}_{e x t}^{\mathrm{a}}$. $\mathbf{f}_{\text {ext }}^{\mathrm{u}}$ is for standard FEM freedoms while $\mathbf{f}_{e x t}^{\mathrm{a}}$ is for enriched freedoms. Vector that includes ordinary degree of freedoms and enriched degree of freedoms are denoted by $\mathbf{u}$ and a respectively. The stiffness matrix associated with the standard FE approximation are $\mathbf{K}^{\mathrm{uu}}$ and $\mathbf{K}^{\mathrm{aa}}$, and coupling between enriched approximation and the standard FE approximation are $\mathbf{K}^{\mathrm{ua}}$ and $\mathbf{K}^{\mathrm{au}}$. For 2D problem, the equivalent nodal force vectors without body force can be expressed as:

$$
\begin{gathered}
\mathbf{f}_{\mathrm{ext}}^{\mathrm{u}}=\int_{\Gamma^{h}} \mathbf{N}^{\mathrm{T}} \overline{\mathbf{t}} \mathrm{d} \Gamma \\
\mathbf{f}_{\mathrm{ext}}^{\mathrm{a}}=\int_{\Gamma^{\mathrm{h}}} \mathbf{N}^{\mathrm{T}}\left(\mathrm{H}_{\Gamma_{c o h}^{c r a c k}}(\mathrm{x}, \mathrm{y})-\mathrm{H}_{\Gamma_{c o h}^{c r a c k}}\left(\mathrm{x}_{\mathrm{i}}, \mathrm{y}_{\mathrm{i}}\right)\right) \overline{\mathbf{t}} \mathrm{d} \Gamma+\mathbf{f}_{\mathrm{coh}}
\end{gathered}
$$

Where, $\mathrm{N}$ represents interpolation function, $\Gamma_{\text {coh }}^{\text {crack }}$ is crack surface due to cohesive force, $\Gamma^{\mathrm{h}}$ is a boundary where the external traction $(\overline{\mathbf{t}})$ is applied and $\mathbf{f}_{\text {coh }}$ is cohesive force vector.

There are two fracture related material parameters, fracture toughness or facture energy criterion and cohesive strength, required by the ECDM. When the crack tip stresses reach the cohesive strength, material damage starts and accumulates. When fracture toughness is reached by strain energy release rate, a new crack is formed and the new crack surface will be created in terms of calculated crack length and the direction of crack growth [31].

Within cohesive zone, crack growth will be judged using a traction separation law. At the discontinuity $\Gamma_{\mathrm{d}}$, tensile crack will occur in cohesive segment where there is positive normal traction component. As a function of displacement jump, both normal and tangential cohesive tractions decrease to zero from their initial values monotonically and can be expressed as:

$$
\mathbf{t}=\left[\begin{array}{l}
\mathrm{t}_{c o h}^{n} \\
\mathrm{t}_{c o h}^{s}
\end{array}\right]=\left[\begin{array}{l}
(1-d) \mathrm{t}_{0}^{n} \\
(1-d) \mathrm{t}_{0}^{s}
\end{array}\right]
$$

Where, $\mathbf{t}_{0}^{n}$ and $\mathbf{t}_{0}^{S}$ are initial normal and shearing traction components respectively. Likewise, $\mathbf{t}_{c o h}^{n}$ and $\mathbf{t}_{c o h}^{s}$ are cohesive tractions in local normal (n) and tangential (s) directions 
respectively, and $\mathrm{d}$ is damage scale factor. The fracture propagation is approximated through released fracture energy according to damage accumulation. Expression for damage scale factor (d) that represents the cohesive behaviour along the crack is:

$$
d=\frac{\frac{1}{2} \int_{\Gamma_{c o h}^{c r a c k}} \tau_{0} \Delta \delta \mathrm{d} \Gamma}{G_{c} l_{\text {crack }}}
$$

Where, $\tau_{0}$ is initial traction, $l_{\text {crack }}$ is characteristic length of a crack, $\Gamma_{\text {coh }}^{\text {crack }}$ is crack surface, $\Delta \delta$ displacement jump and $G_{c}$ is total fracture energy. Considering the computing efficiency, unlike standard XFEM, the additional enriched DoFs are eliminated from original equilibrium equation. However, the effects of enriched degree of freedoms together with the effects from cohesive forces at the discontinuity $\Gamma_{\mathrm{d}}$ are transferred into the fully condensed equilibrium equation which is expressed as follows:

$$
\left(\mathbf{K}^{u u}-\mathbf{K}^{u a}\left(\mathbf{K}^{a a}\right)^{-1} \mathbf{K}^{a u}+\mathbf{K}^{u a}\left(\mathbf{K}^{a a}\right)^{-1}\left(\mathrm{~L}_{1}-\mathrm{L}_{2}\right)\right) \mathbf{u}=\mathbf{f}_{e x t}^{u}
$$

Where, $\mathrm{L}_{1}$ and $\mathrm{L}_{2}$ present the effects from enrichment and cohesive force respectively, they are expressed as:

$$
\begin{aligned}
\mathrm{L}_{1} & =\int_{\Gamma_{\text {coh }}^{\text {crack }}} \mathbf{N}^{T} \boldsymbol{t}_{0} \frac{G_{c} l_{\text {crack }}}{G_{c} l_{\text {crack }}-\int_{\Omega} \frac{1}{2} \boldsymbol{t}_{0} \varepsilon_{0} d \Omega} d \Gamma \mathfrak{R} \\
\mathrm{L}_{2} & =\int_{\Gamma_{\text {coh }}^{\text {crack }}} \mathbf{N}^{T} \boldsymbol{t}_{0} \frac{\int_{\Omega^{2}} \frac{1}{2} t_{0} d \Omega}{G_{c} l_{\text {crack }}-\int_{\Omega} \frac{1}{2} \boldsymbol{t}_{0} \varepsilon_{0} d \Omega} d \Gamma \mathfrak{R}
\end{aligned}
$$

Where, $t_{0}$ is initial cohesive traction, $\varepsilon_{0}$ is initial strain, $\Omega$ is domain, and $\mathfrak{R}$ stands for an operator that represents ultimate equilibrium, and it can be expressed as:

$$
\Re=\frac{1}{\left(\mathbf{K}^{u a}\left(\mathbf{K}^{a a}\right)^{-1} \int_{\Gamma_{c o h}^{c r a c k}} \mathbf{N}^{T} \boldsymbol{t}_{0} d \Gamma\right)^{T} \mathbf{u}}\left(\mathbf{K}^{u a}\left(\mathbf{K}^{a a}\right)^{-1} \int_{\Gamma_{c o h}^{c r a c k}} \mathbf{N}^{T} \boldsymbol{t}_{0} d \Gamma\right)^{T}
$$


In this investigation, principle stress/strain based criteria for judging crack initiation and mixed mode fracture energy based $\mathrm{B}-\mathrm{K}$ criteria proposed by [32] for assessing crack propagation are used in this investigation. A total fracture energy provided by [16] is used for modelling the fracture behaviour of homogenous core.

The above Equs. 1 to 10 are used to develop the extended cohesive damage model (ECDM) as a continuous cohesive damage element through the user subroutine in commercial package ABAQUS implicit code. Simulated cracks can partly or totally break elements at any positions or directions to capture the reality of crack propagation. A nonlinear solver with the line search method selected from ABAQUS is used in this investigation.

To form an ECDM modelling in ABAQUS, a doubly meshing technique is applied to present outcomes from the mesh with user elements by the showing mesh with standard ABAQUS elements. This technique aims to transfer the ECDM outcomes to a standard element based showing mesh for visualisation.

\section{Investigation of fracture mechanism in synthetic foam sandwiches}

The ECDM based modelling technique is used in this investigation to study the detailed fracture mechanisms of synthetic foam core sandwiches with multi-layered cores, and to enhance their damage resilience thus improve their loading capacity. The chosen initial sample is the sandwich panel, having $90 \mathrm{~mm} \times 20 \mathrm{~mm} \times 12 \mathrm{~mm}$ dimensions, manufactured by gluing laminated sheets with a foam core, and tested by three-point bending [16]. This sandwich panel is shown in Figs. 2a and 2b. Considering its symmetric features, a 2D half model with span $45 \mathrm{~mm}$ and thickness $12 \mathrm{~mm}$ ( $2 \mathrm{~mm}$ thick each laminate and $8 \mathrm{~mm}$ thick core) is created to investigate the fracture mechanism under three point bending. Fig. 3 shows a half model of the investigated sandwich panel. $1 \mathrm{~mm}$ elemental size in through thickness is used for modelling face sheets, $0.3 \mathrm{~mm}$ elemental size in through thickness is used for modelling the core. Supporting conditions are applied in the line of three point bending test with simple supports 
at the both ends of the panel. The loading is given through displacement control at the middle of the panel. The loading cell shown in Fig. 3 is modelled using rigid elements with constraint functions. Basic material properties for this investigated sandwich are given below [16]: top and bottom laminates are twelve woven bi-directional layers of carbon fibre-T300. Material properties are given as follows: Young's moduli $\mathrm{E}_{1}=\mathrm{E}_{2}=35000 \mathrm{MPa}$ and $\mathrm{E}_{3}=3150 \mathrm{MPa}$, shear moduli $\mathrm{G}_{12}=\mathrm{G}_{13}=\mathrm{G}_{23}=13257 \mathrm{MPa}$ and Poisson ratios $v_{12}=v_{13}=v_{23}=0.33$. Likewise, the basic homogenous foam core was produced by $3 \mathrm{M}^{\mathrm{TM}}$ using $\mathrm{K} 20$ hollow glass microspheres with binder resin epoxy 520 and 523 hardener. Material properties are comparatively higher compared to material properties of ordinary foams, which are given in Table 1 . It should be noticed that the material strength and fracture energy of the core given in Table 1 are used as inputs of cohesive parameters in ECDM considering the actual fracture in the core only. The fracture energy provided in table 1 is used as a total fracture energy $G_{c}$ to capture the mixed mode fracture with dominated sliding shear cracks in the core and cracks in through thickness way. Mode 1 and Mode 2 cracks related components in the mixed mode B-K criteria are calculated using a constant mixed mode ratio $3 / 4$ together with total $\mathrm{G}_{\mathrm{c}}$.

Table 1: Foam material properties of homogeneous core

\begin{tabular}{|c|c|c|c|c|}
\hline $\begin{array}{c}\text { Young's modulus } \\
(\mathrm{MPa})\end{array}$ & $\begin{array}{c}\text { Poisson } \\
\text { ratio }\end{array}$ & $\begin{array}{c}\text { Tensile strength } \\
(\mathrm{MPa})\end{array}$ & $\begin{array}{c}\text { Shear Strength } \\
(\mathrm{MPa})\end{array}$ & $\begin{array}{c}\text { Fracture Energy } \\
(\mathrm{N} / \mathrm{mm})\end{array}$ \\
\hline 1500 & 0.35 & 26.25 & 9.865 & 0.32 \\
\hline
\end{tabular}

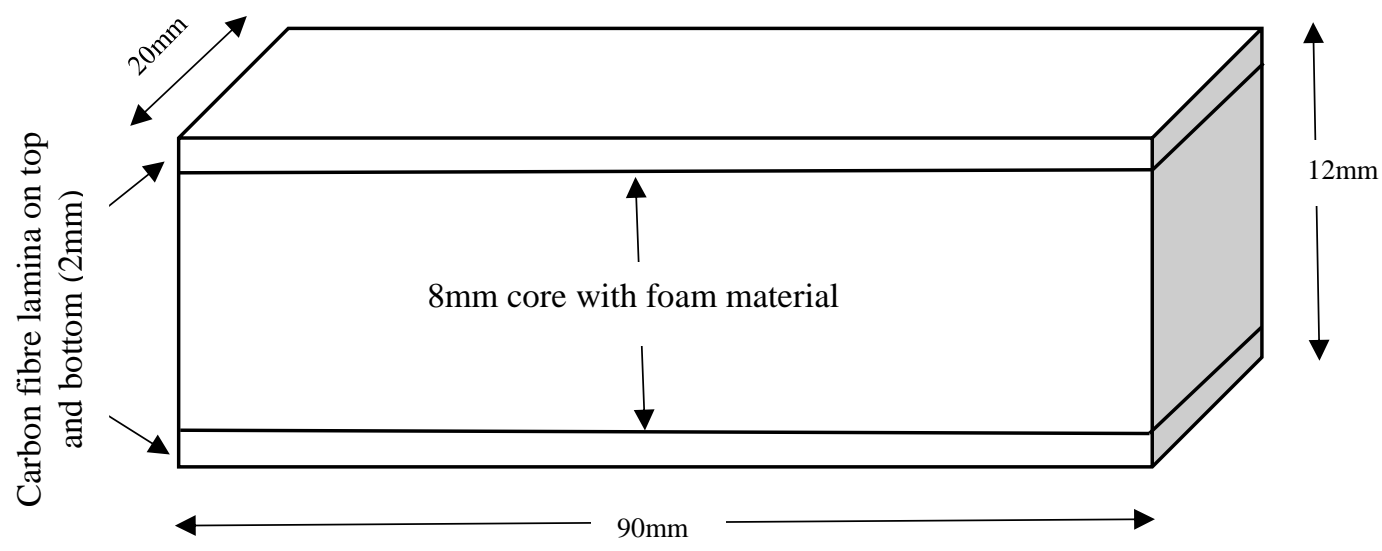


Fig. 2a: A 3D view of sandwich panel with a homogeneous core (not to scale)

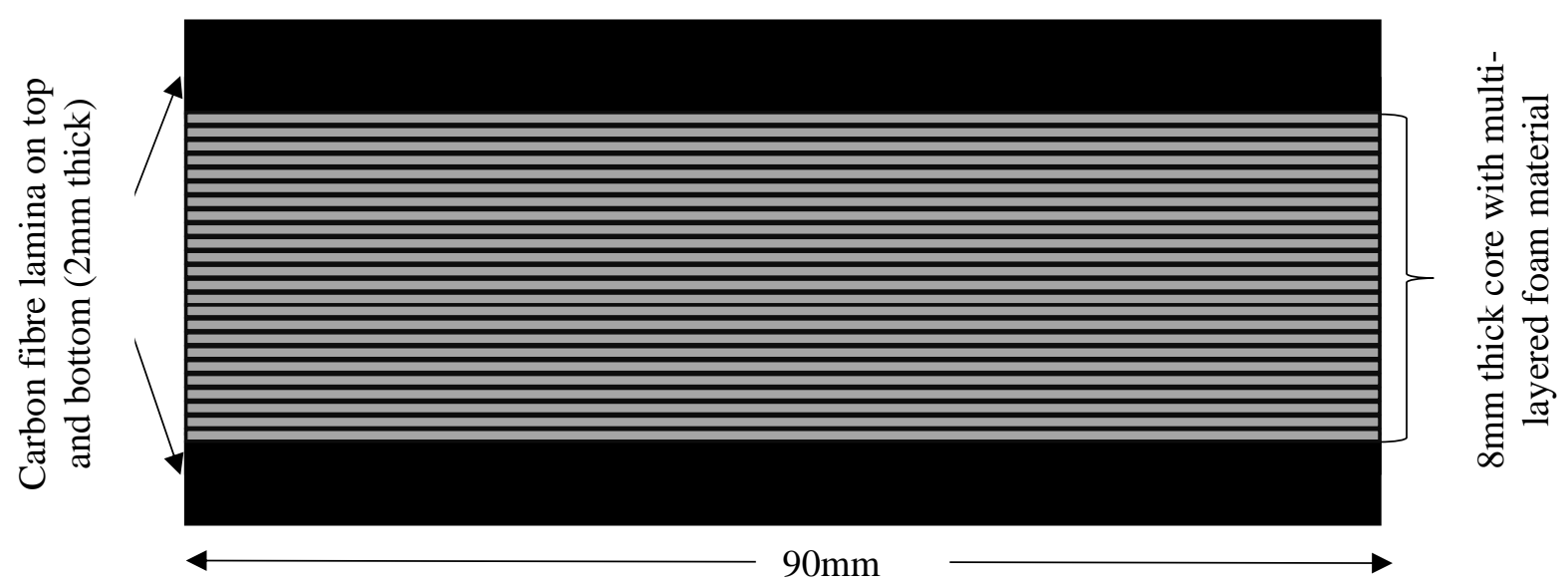

Fig. 2b: A cross-sectional view of sandwich panel with a multi-layered core (not to scale)

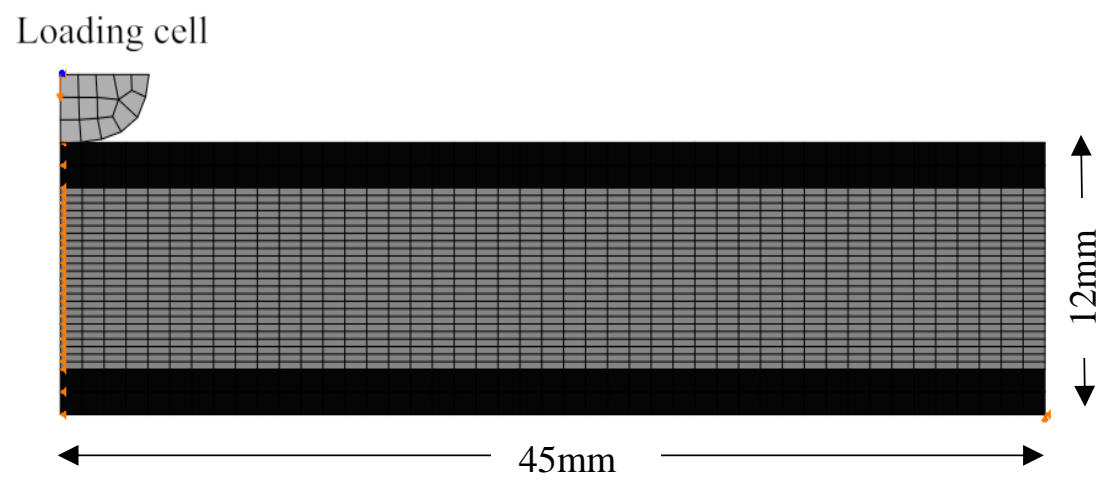

Fig. 3: A half model of sandwich panel

\section{Results and discussion}

\subsection{Homogeneous foam core}

The basic mechanical tests of the sandwich panel with homogenous foam core were reported by [16]. The ECDM prediction of this sandwich panel is compared with experimental results given by [16]. Fig. 4 shows the ECDM predicted failure responses of sandwich panel with homogeneous core and experimental work. It can be seen from Fig. 4 that the ECDM prediction has a very good agreement with experiment work at the initial stiffness and failure load. The failure load predicted by ECDM is $3816.4 \mathrm{~N}$ at $1.3 \mathrm{~mm}$ displacement, which is about 
$3 \%$ higher than experimental result: $3700 \mathrm{~N}$ at $1.2 \mathrm{~mm}$ displacement. The post failure behaviour predicted by ECDM is a very low residual stiffness, it means the panel is totally failed due to the core fractured. However, tested post failure response shows a certain value of reduced residual stiffness. This is perhaps that the test record was stopped considering safety reasons after the main fracture in the right part of the core above the interface between the core and the bottom laminates and a few through thickness cracks occurred, which can be seen from Fig. 5 . Fig. 5 shows tested facture pattern in the right part of the core only, this is possibly caused by some reasons such as material defects, varied supporting conditions, etc., therefore, the left part of the core and face sheets remain the panel a reduced value of residual stiffness. It should be noted that there was a thin layer of core material left on the cracked surface above the corebottom sheet interface [16], which means the dominated failure is the sliding shear fracture in the core along a path above the core-bottom sheet interface instead of pure debonding at the interface.

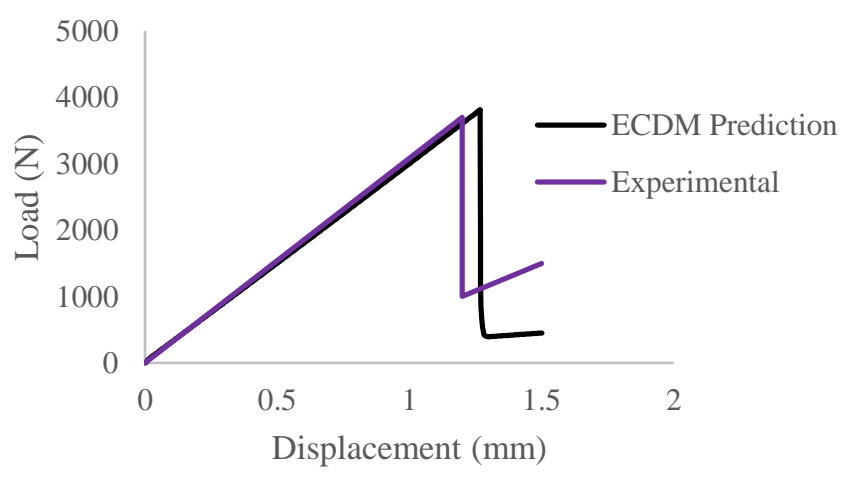

Fig. 4: Failure responses of sandwich panel with a homogeneous core given by ECDM and experimental work

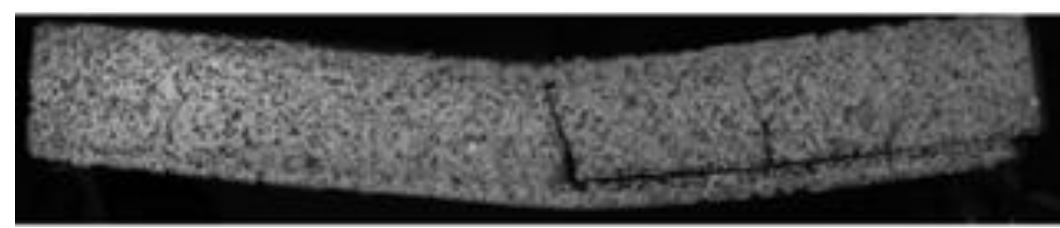

Fig. 5: Tested failure mode of the sandwich panel with homogeneous core [16] 

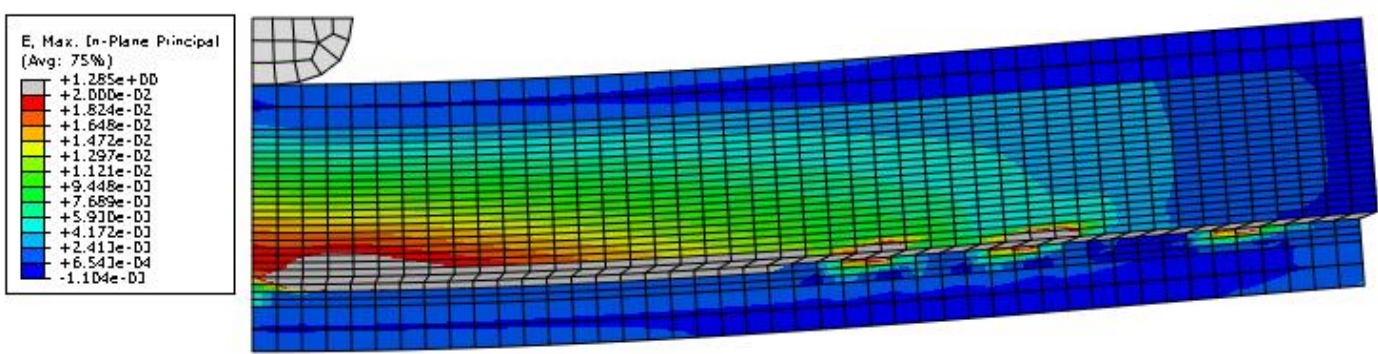

Fig. 6: The ECDM predicted failure mode of the half model of the sandwich panel with homogeneous core

Both experimental observation shown in Fig. 5 and ECDM prediction shown Fig. 6 found that the dominated fracture is sliding shear fracture within the core along a path above the corebottom sheet interface. It is core fracture instead of pure debonding at the interface. It is also predicted that the main fracture path is about $1 \mathrm{~mm}$ away from the core-bottom sheet interface, and the fracture path has variable gap between $0.6 \mathrm{~mm}$ to $1.5 \mathrm{~mm}$ to the interface instead of a simple straight line. The fracture path also includes some cracks in through thickness way between the end and the middle of the panel. These unknown fracture paths would be difficult to use classical cohesive zone model $(\mathrm{CZM})$ in simulation because CZM needs pre-prepared crack paths. ECDM predicted fracture paths are automated and agree with experimental observation. The fracture paths can be calculated using crack length and crack propagation direction in cracked elements. The CPU time spent on this simulation is 417 seconds. Fig. 6 presents the principal strain contour in which the grey colour represents fracture mode in the core at the failure load in load-displacement curve shown in Fig. 4. Fracture initiates at the edge of the panel because of the concentrated shear stresses and propagates towards the middle of the panel in terms of fracture energy released. When crack grows in the core along a path above the core-bottom sheet interface, a few through thickness cracks follow in the way moving up from the sliding shear fracture path in the core. When the sliding shear fracture tip closes to the middle of the panel there are more through thickness cracks occurred, which are caused by high values of both tensile and shear stresses in the middle area of the core. The ECDM 
prediction gives a trend that a big crack at the middle of the panel would grow up in the through thickness direction to the top when sliding shear fracture propagates towards the middle area, which indicates that sliding shearing dominated fracture would be followed by the tensile failure related through thickness cracks in the middle area of the panel. This prediction agrees with the experimental observation shown in Fig. 5. However, Fig. 6 mainly shows sliding shear fracture in the core above the core-bottom sheet interface. A few through thickness cracks between the edge and the middle of the panel are also predicted and shown in Fig. 6, which are

consistent with the experimental observation shown in Fig. 5. It should be noticed that the material property of the core is much lower than the laminate sheet, therefore, sliding shear fracture occurs in the core and slightly moves up from the materials mismatched core-bottom sheet interface because of the effect of strong fibre laminated sheet. Hence, the failure is mainly caused by sliding shearing in the core above the core-bottom sheet interface.

It should also be noticed that Fig. 5 shows an asymmetric failure pattern of tested sandwich panel. Fractures including sliding shear cracks and cracks in vertical way only appear in the right part of panel. This could be due to material imperfections or attributes to other reasons, e.g. cracks initiate near to the indenter / supports and initiating in the areas of foam crushing. However, ECDM with B-K fracture energy criteria and a fixed mixed mode ratio has predicted the dominated sliding shear cracks and a few short cracks or crack tendencies in vertical way shown in Fig. 6.

\subsection{Four-layered core with varied Young's modulus}

A limited loading capacity of the sandwich panel with a homogeneous core can be seen from section 4.1. Previous work [16] also investigated the sandwich panel with a 4-layered core to improve mechanical behaviour. Four layers were arranged in a symmetrical way from the core-bottom sheet interface to the core-top sheet interface. Two layers in the middle of the core remain the same material properties with the homogenous core. Other two layers next to 
the bottom and the top laminates have increased core material properties by $27 \%$ from homogenous foam material [16], which aims to reduce the mismatched material gap at the interfaces. The ECDM modelling is used to simulate this tested sandwich sample with a 4layered core, and material properties given in Table 2 are used in modelling simulations.

Fig. 7 shows failure response predicted by ECDM together with experimental work [16]. Results of the case of homogenous core from tests and ECDM are also shown in Fig. 7 for comparison. In general, the ECDM prediction agrees with test work very well at both initial stiffness and failure point. The failure load predicted by ECDM is $4824 \mathrm{~N}$ at $1.52 \mathrm{~mm}$ displacement, which is about $7 \%$ higher than the experimental result: $4500 \mathrm{~N}$ load and $1.5 \mathrm{~mm}$ displacement. Similar to the case of a homogenous core, the ECDM predicted post failure response is a very low residual stiffness. It can be seen from Fig. 7 that the tested response at the initial stiffness stage seems slightly nonlinear due to perhaps unstable supporting rigs, and no post failure response were recorded by [16]. The loading capacity of the sandwich panel with 4-layered core is increased from the case of a homogenous core. Increments of $22 \%$ and $26 \%$ were conducted from experimental tests and the ECDM prediction respectively.

Table 2: Material properties used in the 4-layered core

\begin{tabular}{|c|c|c|c|c|c|}
\hline Layer & $\begin{array}{c}\text { Young's } \\
\text { modulus (MPa) }\end{array}$ & $\begin{array}{c}\text { Poisson } \\
\text { ratio }\end{array}$ & $\begin{array}{c}\text { Normal strength } \\
(\mathrm{MPa})\end{array}$ & $\begin{array}{c}\text { Shear strength } \\
(\mathrm{MPa})\end{array}$ & $\begin{array}{c}\text { Fracture energy } \\
(\mathrm{N} / \mathrm{mm})\end{array}$ \\
\hline 1 & 1900 & 0.36 & 33.25 & 12.495 & 0.41 \\
\hline 2 & 1500 & 0.35 & 26.25 & 9.865 & 0.32 \\
\hline & & & & & 0.32 \\
\hline 3 & 1500 & 0.35 & 26.25 & 9.865 & 0.41 \\
\hline 4 & 1900 & 0.36 & 33.25 & 12.495 & \\
\hline
\end{tabular}

Fig. 8 shows the failure mode predicted by ECDM at the failure load. It is a sliding shear fracture dominated failure along the path above the core-bottom sheet interface represented by grey colour. Basic features of this failure mode are similar to the case of homogenous core, however, as sliding shear facture propagates from the edge to the middle of the panel there are more cracks caused by sliding shearing in large failure areas and tension in the area close to 
the middle of the panel. Almost sliding shear facture and through thickness cracks are at the first layer in the core above the core-bottom sheet interface. It should be noticed that this failure mode with bigger cracked areas needs a higher value of strain energy release rate, which thus conducts an increased failure load compared to the case of homogenous core.

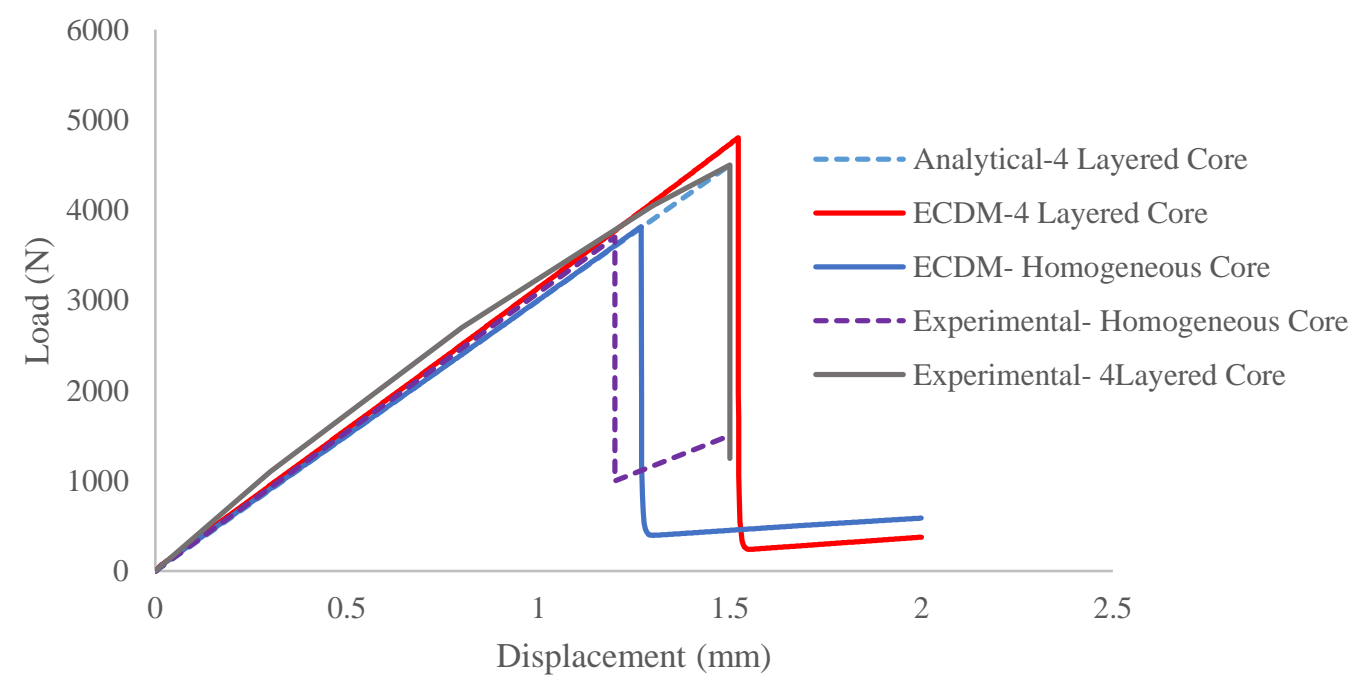

Fig. 7: Failure responses of sandwich panel with a 4-layered core given by ECDM and experimental work
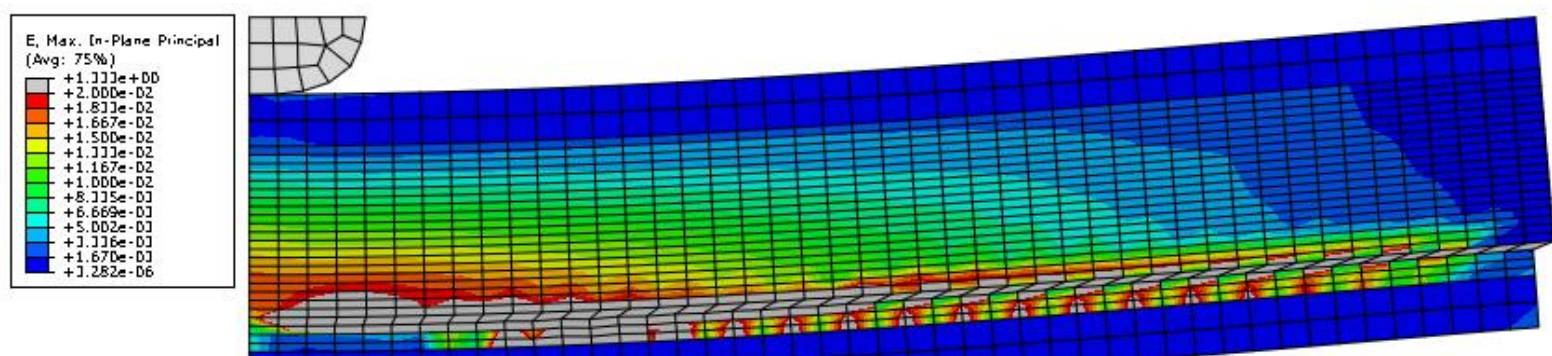

Fig. 8: Failure mode of half sandwich panel with a 4-layered core predicted by ECDM

\subsection{Sandwich panel with a multi-layered core}

Examples in sections 4.1 and 4.2 verified the capability of ECDM in prediction of fracture mechanisms of synthetic foam sandwiches with a homogeneous core and a 4-layered 
core respectively. Section 4.2 presented that the sandwich panel with a 4-layered core increases loading capacity between $22 \%$ and $26 \%$ compared to the case of homogenous core. Further investigation in this section focuses on the case of the sandwich with a multi-layered core, which aims to reach the ultimate loading capacity of the investigated synthetic foam sandwiches. This investigation is based on the ECDM prediction. A core with varied number of layers, 6, 8, 12 and 24, are chosen in this modelling investigation. Varied number of layers are always arranged in symmetric way from core-bottom sheet interface to the core-top sheet interface. Two layers in the middle of the core remain the same material properties with that in homogenous core. The material properties including Young's modulus, strength and fracture energy are increased proportionally. The layers next to the bottom and the top sheet are proposed to have $100 \%$ increased material properties from the layers in the middle of the core to largely reduce mismatched materials gap at the interfaces. As an example, incremental percentages of material properties distributed symmetrically in the 24-layered core is $9.09 \%$.

Table 3: Distributed material properties in the 24-layered core

\begin{tabular}{|c|c|c|c|c|c|c|c|c|c|c|c|c|}
\hline Layer & 1 & 2 & 3 & 4 & 5 & 6 & 7 & 8 & 9 & 10 & 11 & 12 \\
\hline $\begin{array}{c}\% \\
\text { Increment }\end{array}$ & 100 & 90.9 & 81.81 & 72.72 & 63.63 & 54.54 & 45.45 & 36.36 & 27.27 & 18.18 & 9.09 & 0 \\
\hline Layer & 13 & 14 & 15 & 16 & 17 & 18 & 19 & 20 & 21 & 22 & 23 & 24 \\
\hline $\begin{array}{c}\% \\
\text { Increment }\end{array}$ & 0 & 9.09 & 18.18 & 27.27 & 36.36 & 45.45 & 54.54 & 63.63 & 72.72 & 81.81 & 90.9 & 100 \\
\hline
\end{tabular}

Fig. 9 presents the ECDM predicted failure responses of the sandwich panel with a multilayered core. The varied number of graded layers are 6, 8, 12 and 24. Experimental results from the case of a core with homogenous and a core with 4-graded layers are also given in Fig. 9 for comparison. It can be seen from Fig. 9 that all failure responses of sandwiches with varied multi-layered cores show a similar load-displacement curve with a big drop when the load reaches the failure load then followed by a very low residual stiffness. However, the value of 
failure load of this investigated sandwich panel is significantly increased when the core has above 6 graded layers. The increased percentage varies from $62 \%, 70 \%, 62 \%$ and $60 \%$ respectively when number of layers in the core varies as $6,8,12$, and 24 compared to the case of homogeneous core.

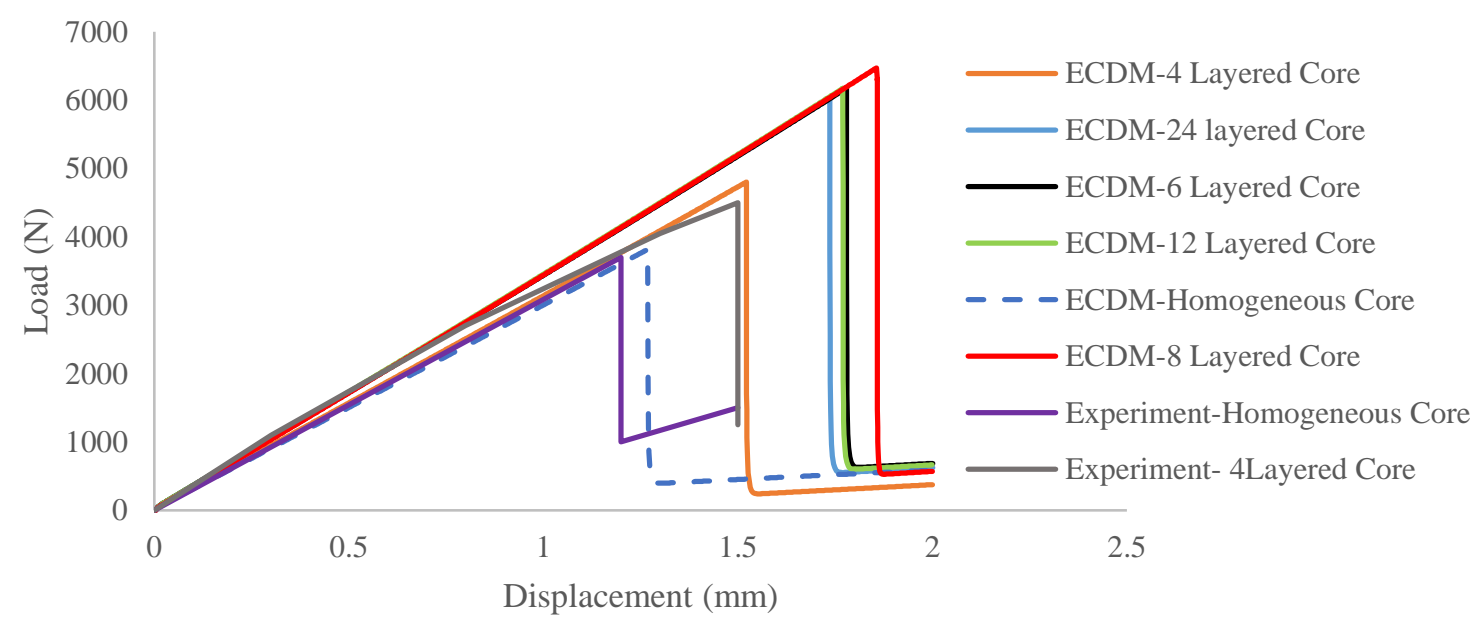

Fig. 9: The ECDM predicted failure responses of sandwich panel with multi-layered cores
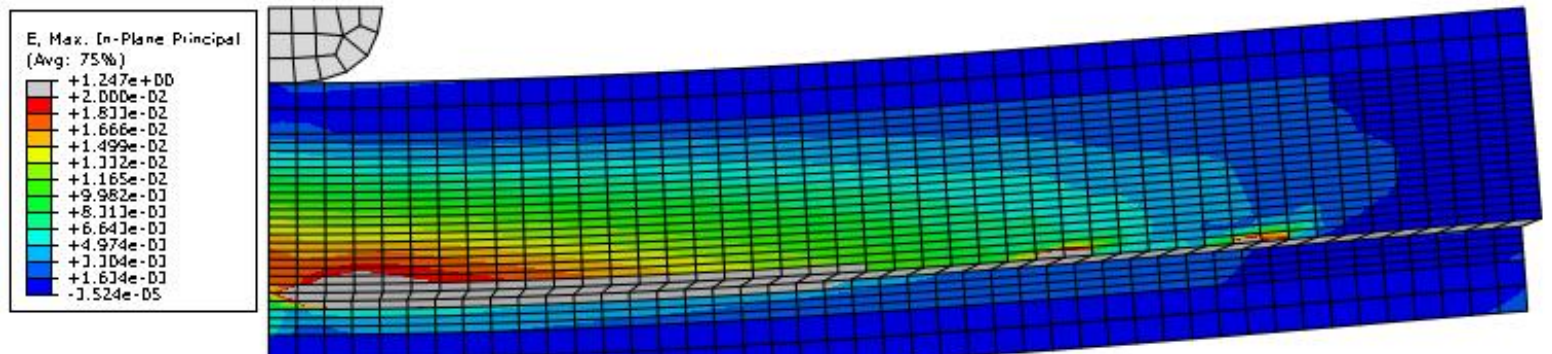

Fig. 10: The ECDM predicted failure mode of sandwich panel with a 6-layered core
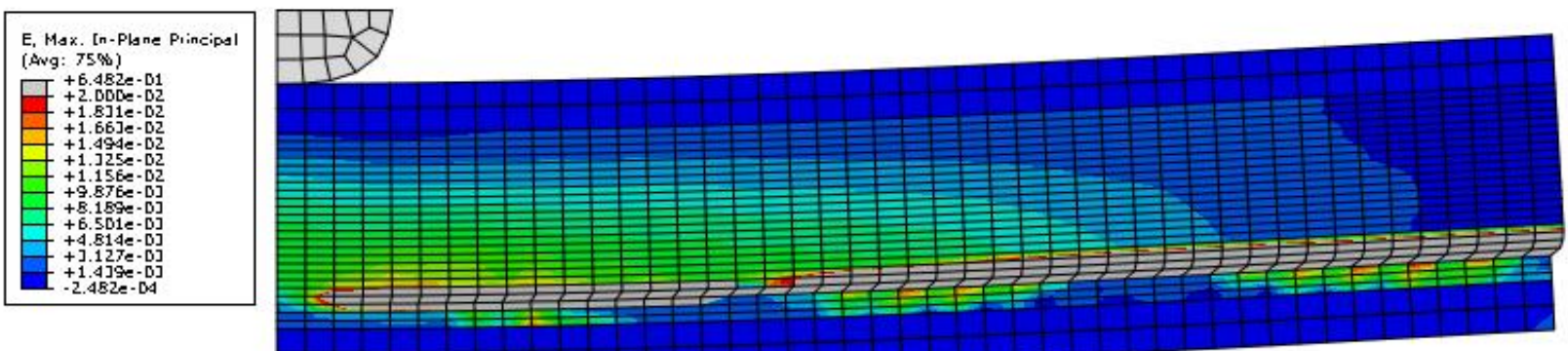

Fig. 11: The ECDM predicted failure mode of sandwich panel with an 8-layered core 

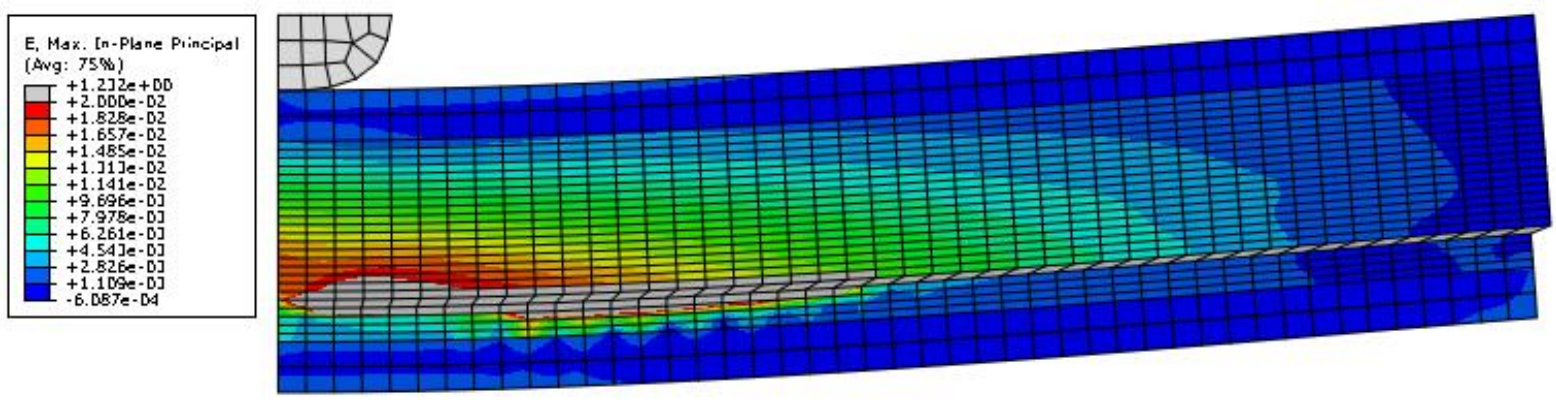

Fig. 12: The ECDM predicted failure mode of sandwich panel with a 12-layered core
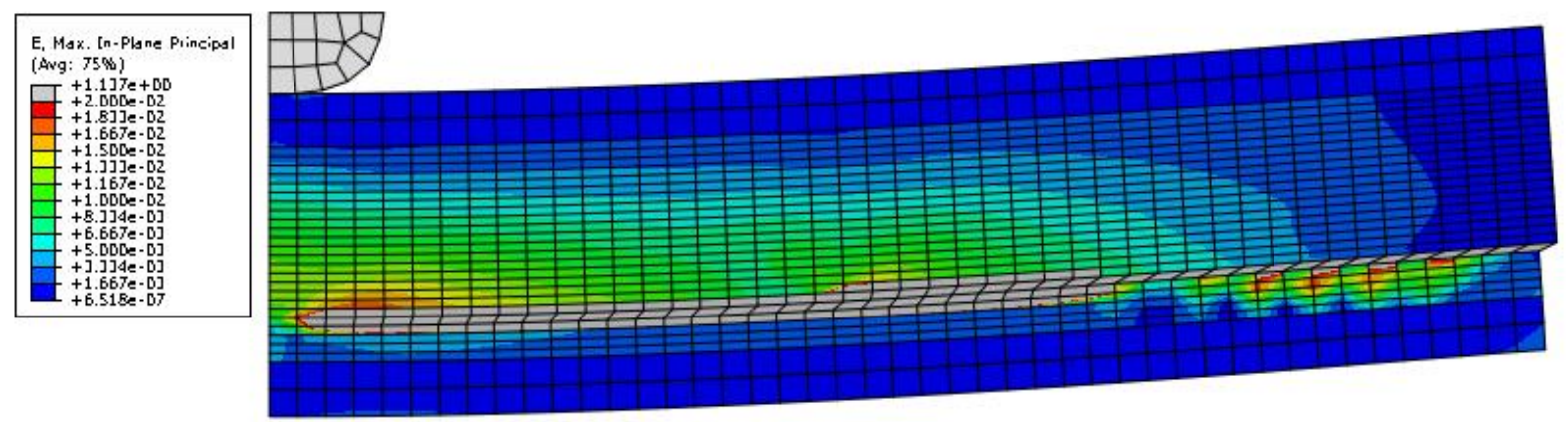

Fig. 13: The ECDM predicted failure mode of sandwich panel with a 24-layered core

Figs. 10 to 13 show the failure modes, represented by grey colour, of the synthetic foam sandwiches with multi-layered cores. These figures reveal that all failure modes are sliding shear fracture dominated, which initiate from the side edge along a path above the core-bottom sheet interface and propagate towards the middle of the panel. The failure modes from 6layered core and 12-layerd core shown in Figs. 10 and 12 respectively are very similar. This agrees with their almost same failure response shown in Fig. 9. The fracture in the first quarter length accounted from the edge of the panel is almost single crack propagation caused mainly by sliding shearing. When sliding shear fracture propagates to the middle area of the panel, failure modes change to the mixed mode fracture caused by tension and shear, and there are more elements failed in the middle area of the panel. The failure mode of 8-layered core shown in Fig. 11 looks different from that in Figs 10 and 12 in some extent. It is still sliding shear fracture dominated failure, however, it is a mixed mode fracture caused by shear and tension 
through the fracture propagation way from the edge to the middle of the panel. There are much more elements failed along the fracture path above the core-bottom sheet interface. This is the reason for the loading capacity of sandwich panel with an 8-layered core reaches the highest value shown in Fig. 9 compared to other cases. In the case of 24-layered core, the failure mode shown in Fig. 13 is generally similar to other cases, however, failed area or elements at the failure load is less than other cases, which is associated with a slightly low failure load shown in Fig. 9. The CPU time spent on the simulation of the 8-layered core case is 1427 seconds which is longer compared to other cases: 241 seconds and 214 seconds for 12 and 24-layered cases respectively.

It should be noticed that the initial stiffness of sandwich panels with multi-layered cores is increased because of increased material properties proportionally compared to the cases with a homogeneous core and a 4-layered core. It is reasonable to investigate the case of homogeneous core using average material properties conducting from proportionally increased material properties in the multi-layered cores. The values of average material properties given in Table 4 are calculated based on original homogeneous foam material properties and $100 \%$ increased properties in the multi-layered core shown in Table 3. It is found that the case of the core with average material property (named as average core) has similar behaviour with that in the case of a homogeneous core. Fig. 14 shows a failure response for the case of the core with averaged foam material properties. It can be seen from Fig. 14 that the predicted initial stiffness for the average core agrees to multi-layered core very well. The predicted failure load is higher than that of the 4-layered core by $15 \%$, but lower than that in all cases when the core has above 6 graded layers. Notably, it is lower than an 8-layered core by $16 \%$. This confirms that the multi-layered core has advantages compared to single layered core. It should be noticed that all multi-layered core cases from 6 to 24 layers have almost identical average stiffness, strength and fracture energy. 
Table 4: Average material properties of homogeneous core

\begin{tabular}{|c|c|c|c|c|}
\hline $\begin{array}{c}\text { Young's modulus } \\
(\mathrm{MPa})\end{array}$ & Poisson ratio & $\begin{array}{c}\text { Normal strength } \\
(\mathrm{MPa})\end{array}$ & $\begin{array}{c}\text { Shear strength } \\
(\mathrm{MPa})\end{array}$ & $\begin{array}{c}\text { Fracture energy } \\
(\mathrm{N} / \mathrm{mm})\end{array}$ \\
\hline 2250 & 0.355 & 39.4 & 14.4 & 0.48 \\
\hline
\end{tabular}

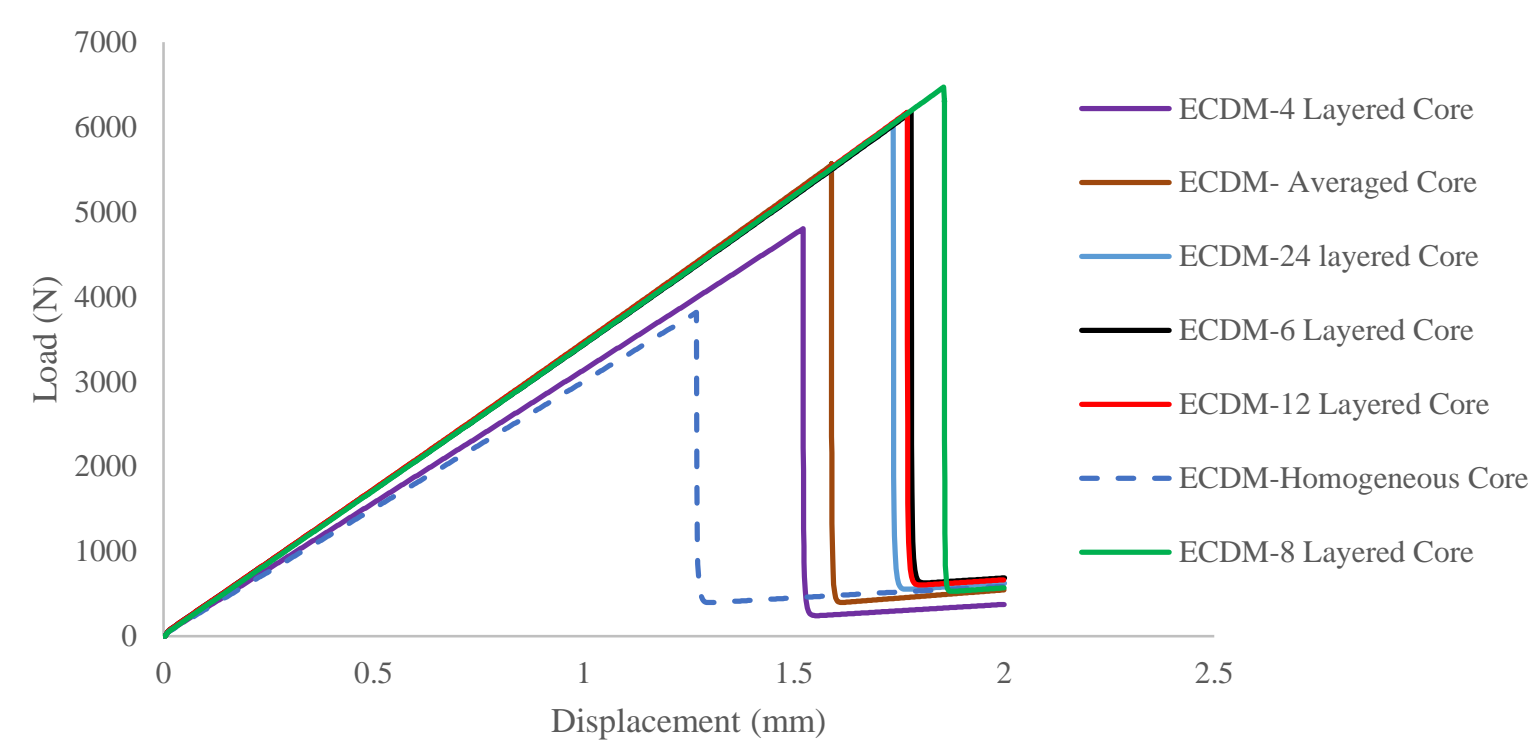

Fig. 14: The ECDM predicted failure responses of the sandwich panels with multi-layered cores and a core with average material properties

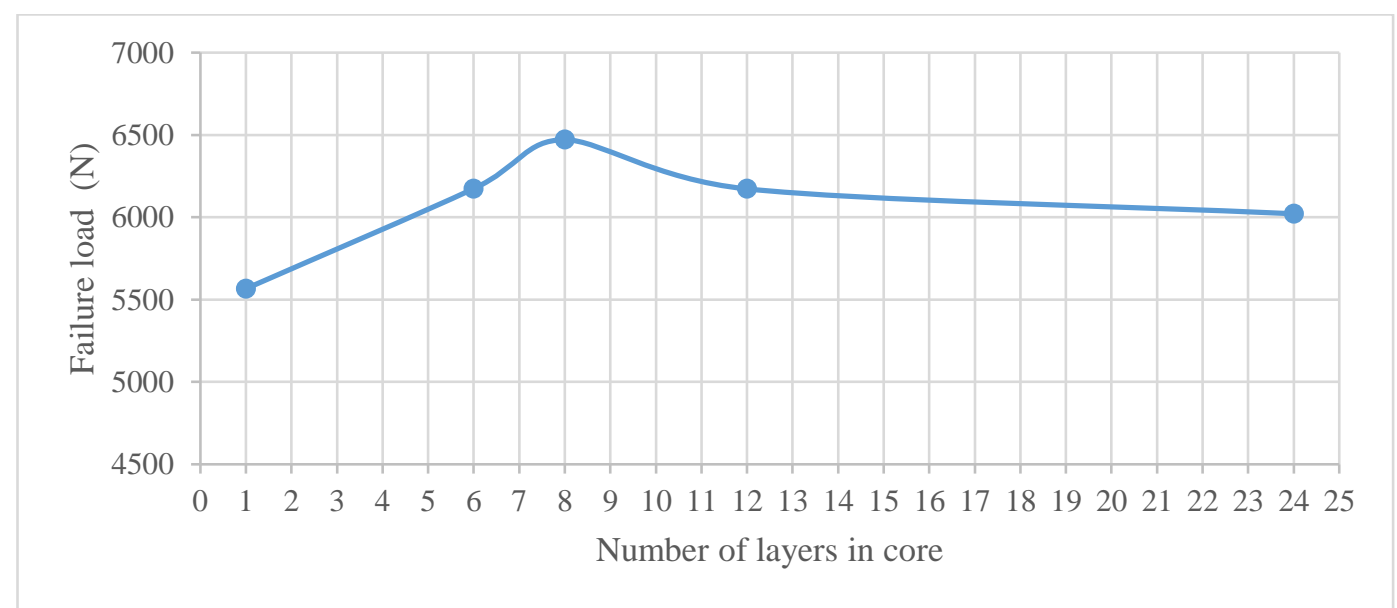

Fig. 15: Variation of failure load against the number of graded layers in the core

Using the results of predicted failure loads shown in Fig. 14, the correlation between the loading capacities of synthetic foam sandwiches and the number of graded layers in the core 
are conducted. Fig. 15 shows variation of failure load against the number of graded layers in the core. It can be seen from Fig. 15 that failure load increases stably and rapidly as the number of layers in the core increases; it reaches the peak value $6470.74 \mathrm{~N}$ when the core has 8 multilayers, then it gradually comes down after 8-layers and trends to be a constant failure load of about $6000 \mathrm{~N}$ after 24-layers. Obviously, it can be seen from Fig. 15 that the sandwich panel with 8-layered core shows a superior loading capacity compared to other cases of multi-layered core, which is associated with the biggest failure area represented by grey colour in Fig. 11. This failure mode with big failed areas needs a high value of strain energy release rate, hence failure load in 8-layered core case is higher than other cases. It is noted that layer 1 case shown in Fig. 15 is the case of the homogenous core with average material properties. It should be noticed that the predicted failure loads of the sandwich panels with multi-layered cores are varied according varied number of layers in the core. This directly relates to the failed areas or the mount of cracks at the failure point. Predicted failed area increases as the number of layers in the core increases until 8 layers then slightly decreases after that but trends to be a less changed failed area after 24 layers.

\section{Conclusions and the future work}

The detailed fracture mechanisms of synthetic foam sandwiches with multi-layered cores are investigated using ECDM. The capability of the ECDM in prediction of fracture mechanisms in synthetic foam sandwiches is verified by the experimental work of the foam sandwiches with homogenous core and 4-layered core. Through prediction of the failure responses of the core with graded multi-layers, it is first time that a correlation between the failure load and the number of layers in the core is explored. In general, the multi-layered core enhances damage resilience in synthetic foam sandwiches thus improves their loading capacities. It is found that the failure load in the case of 8 -layered core is increased by $70 \%$ compared to original homogenous core and $16 \%$ compared to average homogenous core. As 
foam materials are cheaper compared to fibre materials, this prediction of increased loading capacity without changing quantity and quality of fibre laminates gives a cost-effective solution to enhance synthetic foam sandwiches in the future.

Although the ECDM with a fixed mixed mode ratio captured the dominated sliding shear cracks and short tensile vertical cracks well in this investigation, it would be worth investigating different mixed mode ratios and a modified mixed-mode cohesive formulation [33] to improve the prediction of tensile cracks in through thickness direction in the future. This paper investigated synthetic foam core sandwiches, as honeycomb sandwiches are also widely used in engineering structures, thus they will be investigated using ECDM in the future.

\section{References}

[1] Chandra N, Gopal KN, Raja S. Vibro-acoustic response of sandwich plates with functionally graded core. Acta Mechanica. 2017;228:2775-89.

[2] Hassanpour Roudbeneh F, Liaghat G, Sabouri H, Hadavinia H. Experimental investigation of impact loading on honeycomb sandwich panels filled with foam. International Journal of Crashworthiness. 2018:1-12.

[3] Shawkat W, Honickman H, Fam A. Investigation of a novel composite cladding wall panel in flexure. Journal of composite materials. 2008;42:315-30.

[4] Correia J, Garrido M, Gonilha J, Branco F, Reis L. GFRP sandwich panels with PU foam and PP honeycomb cores for civil engineering structural applications: effects of introducing strengthening ribs. International Journal of Structural Integrity. 2012;3:127-47.

[5] Zoghi M. The international handbook of FRP composites in civil engineering: CRC Press, 2013.

[6] Tan K-T, Khan M. Impact and post-impact flexural behavior of composite sandwich structures in extreme low temperature arctic conditions. 12th International Conference on Sandwich Structures ICSS-12: Proceedings: EPFL-CCLab Composite Construction Laboratory; 2018. p. 89-91. 
[7] Mao L, Guo R, Song Y, Chiang F-p. Full-field surface and interior deformation measurement of sandwich core material using digital speckle photography. 12th International Conference on Sandwich Structures ICSS-12: Proceedings: EPFL-CCLab Composite Construction Laboratory; 2018. p. 18-20.

[8] Rao S, Jayaraman K, Bhattacharyya D. Short fibre reinforced cores and their sandwich panels: Processing and evaluation. Composites Part A: Applied Science and Manufacturing. 2011;42:1236-46.

[9] Stocchi A, Colabella L, Cisilino A, Álvarez V. Manufacturing and testing of a sandwich panel honeycomb core reinforced with natural-fiber fabrics. Materials \& Design. 2014;55:394403.

[10] Vitale JP, Francucci G, Stocchi A. Thermal conductivity of sandwich panels made with synthetic and vegetable fiber vacuum-infused honeycomb cores. Journal of Sandwich Structures \& Materials. 2016;19:66-82.

[11] Etemadi E, Khatibi AA, Takaffoli M. 3D finite element simulation of sandwich panels with a functionally graded core subjected to low velocity impact. Composite Structures. 2009;89:28-34.

[12] Apetre N, Sankar B, Ambur D. Low-velocity impact response of sandwich beams with functionally graded core. International Journal of Solids and Structures. 2006;43:2479-96.

[13] Kashtalyan M, Menshykova M. Three-dimensional elasticity solution for sandwich panels with a functionally graded core. Composite Structures. 2009;87:36-43.

[14] Udupa G, Rao SS, Gangadharan K. Functionally graded composite materials: an overview. Procedia Materials Science. 2014;5:1291-9.

[15] Akavci S. Mechanical behavior of functionally graded sandwich plates on elastic foundation. Composites Part B: Engineering. 2016;96:136-52.

[16] Capela C, Ferreira J, Costa J. Effect of the foam core density on the bending response on sandwich composites. Fibers and Polymers. 2013;14:597-602.

[17] Avila AF. Failure mode investigation of sandwich beams with functionally graded core. composite structures. 2007;81:323-30. 
[18] Lashkari M, Rahmani O. Bending behavior of sandwich structures with flexible functionally graded core based on high-order sandwich panel theory. Meccanica. 2016;51:1093-112.

[19] Icardi U, Ferrero L. Optimisation of sandwich panels with functionally graded core and faces. Composites Science and Technology. 2009;69:575-85.

[20] Elices M, Guinea G, Gomez J, Planas J. The cohesive zone model: advantages, limitations and challenges. Engineering fracture mechanics. 2002;69:137-63.

[21] Blackman B, Hadavinia H, Kinloch AJ, Williams J. The use of a cohesive zone model to study the fracture of fibre composites and adhesively-bonded joints. International Journal of Fracture. 2003;119:25-46.

[22] Swati RF, Hua W, Elahi H, Khan A. Extended finite element method damage analysis of carbon fiber reinforced composites and crack propagation in mixed-mode using multiscale method and implementation of the method using ABAQUS extended finite element method damage analysis of carbon. 4th International conference on mechanics and mechatronics research, Xian IOP2017.

[23] Li X, Chen J. An extended cohesive damage model for simulating arbitrary damage propagation in engineering materials. Computer Methods in Applied Mechanics and Engineering. 2017;315:744-59.

[24] Li X, Chen J. An extended cohesive damage model for simulating multicrack propagation in fibre composites. Composite Structures. 2016;143:1-8.

[25] Oliver J, Huespe A, Samaniego E. A study on finite elements for capturing strong discontinuities. International journal for numerical methods in engineering. 2003;56:2135-61.

[26] Rudraraju S, Salvi A, Garikipati K, Waas AM. Predictions of crack propagation using a variational multiscale approach and its application to fracture in laminated fiber reinforced composites. composite structures. 2012;94:3336-46.

[27] Lin S, Nguyen N, Waas AM. Application of continuum decohesive finite element to progressive failure analysis of composite materials. composite structures. 2019;212:365-80. 
[28] Li X, Chen J. A highly efficient prediction of delamination migration in laminated composites using the extended cohesive damage model. Composite Structures. 2017;160:71221.

[29] Li X, Chen J. The implementation of the extended cohesive damage model for multicrack evolution in laminated composites. Composite Structures. 2016;139:68-76.

[30] Li X, Chen J. A highly efficient numerical approach: extended cohesive damage model for predicting multicrack propagation. Materials at High Temperatures. 2017;34:371-85.

[31] Rudraraju SS, Salvi A, Garikipati K, Waas AM. In-plane fracture of laminated fiber reinforced composites with varying fracture resistance: Experimental observations and numerical crack propagation simulations. International Journal of Solids and Structures. 2010;47:901-11.

[32] Benzeggagh ML, Kenane M. Measurement of mixed-mode delamination fracture toughness of unidirectional glass/epoxy composites with mixed-mode bending apparatus. Composites Science and Technology. 1996;56:439-49.

[33] Nhung Nguyen, Waas, Anthony M., A novel mixed-mode cohesive formulation for crack growth analysis, COMPOSITE STRUCTURES, 156, 253-262, 2016. 